\title{
Hedgehog signaling pathway mediates invasion and metastasis of hepatocellular carcinoma via ERK pathway
}

\author{
Jing-tao LU\#, Wen-di ZHAO\#, Wei HE, Wei WEI* \\ Institute of Clinical Pharmacology, Anhui Medical University, Key Laboratory of Anti-inflammatory and Immunopharmacology of \\ Education Ministry, Anhui Engineering Technology Research Center of Anti-inflammatory and Immunodrugs, Hefei 230032, China
}

Aim: To investigate the role of Hedgehog $(\mathrm{Hh})$ signaling pathway in the invasion and metastasis of human hepatocellular carcinoma (HCC).

Methods: Eighty six HCC tissues samples and HCC cell line Bel-7402 were examined. The protein expression of sonic hedgehog (Shh), nuclear glioma-associated oncogene-1 (Gli1), MMP-9 and p-ERK1/2 in HCC was analyzed using immunohistochemistry and Western blot analysis. Boyden chamber assay and wound-healing assay were used to quantify the invasion and metastasis of Bel-7402 cells. Results: In 86 HCC tissue samples, the positive ratio of Shh and nucleus Gli1 was $67.44 \%$ (58/86) and 60.47\% (52/86), respectively; the expression of nucleus Gli1 was correlated with the tumor pathological grade $(P=0.034)$, and with the ability of the tumor to invade and metastasize $(P=0.001)$; the expression of nucleus Gli1 was also correlated with $\mathrm{p}-\mathrm{ERK} 1 / 2(P=0.031)$ and with MMP-9 $(P=0.034)$. Neither Shh, nor nucleus Gli1 was observed in normal liver tissue. KAAD-cyclopamine (KAAD-cyc), a specific inhibitor of the Hh pathway, at the concentrations of 1 and $4 \mu \mathrm{mol} / \mathrm{L}$ inhibited the invasion and migration of Bel-7402 cells and decreased the expression of Gli1 in nucleus and MMP-9, p-ERK1/2 proteins in Bel-7402 cells. On the other hand, Shh, a ligand of the Hh pathway, at the concentration of $0.5 \mu \mathrm{g} / \mathrm{mL}$ produced opposite effects. The MAPK pathway inhibitors U0126 and PD98059 at the concentrations of 5 and 10 $\mu \mathrm{mol} / \mathrm{L}$ inhibited invasion and metastasis of Bel-7402 cells induced by Shh, and decreased the expression of p-ERK1/2 and MMP-9. However, U0126 and PD98059 had no effect on the expression of Gli1.

Conclusion: Hh signaling pathway mediates invasion and metastasis of human HCC by up-regulating the protein expression of MMP-9 via ERK pathway.

Keywords: human hepatocellular carcinoma; invasion and metastasis; hedgehog signaling pathway; nuclear glioma-associated oncogene-1 (Gli1); ERK pathway; MMP-9

Acta Pharmacologica Sinica (2012) 33: 691-700; doi: 10.1038/aps.2012.24; published online 30 Apr 2012

\section{Introduction}

Hepatocellular carcinoma (HCC) is the common primary cancer with a multifaceted molecular pathogenesis. HCC has become the fifth most prevalent malignancy worldwide and the third leading cause of cancer-related death, most importantly, the incidence of HCC is increasing ${ }^{[1,2]}$, and $82 \%$ of cases are in developing countries, with $55 \%$ in China alone ${ }^{[3]}$. Invasion and metastasis are two fundamental properties, which determine the prognosis of the HCC patients ${ }^{[4,5]}$. Many signaling pathways are thought to be involved in the development and invasion of HCC, including the MAPK pathway ${ }^{[6,7]}$,

\footnotetext{
\# These authors contributed equally to this work.

* To whom correspondence should be addressed.

E-mail wwei@anhu.edu.cn

Received 2011-12-08 Accepted 2012-02-29
}

phosphatidylinositol-3 kinase (PI3K)/AKT/mammalian target of rapamycin (mTOR) pathway ${ }^{[8-10]}$, the wnt/beta-catenin pathway $^{[9,11]}$, hepatocyte growth factor/c-MET pathway ${ }^{[12,13]}$, hedgehog $(\mathrm{Hh})$ signaling pathway, and so on.

Hh signaling pathway is a highly conserved system, which plays a crucial role in tissue patterning, cell differentiation and proliferation $^{[14]}$. Hedgehog, including sonic hedgehog (Shh), Indian hedgehog (Ihh), and desert hedgehog (Dhh), appear to bind to a transmembrane receptor protein, known as Patched (Ptc), which in the absence of Shh exerts an inhibitory effect on the seven transmembrane receptor smoothened (Smo). Binding of Shh to Ptc alleviates the inhibitory effect of Ptc on Smo. Once activated, Smo induces a complex series of intracellular reactions that targets the glioma-associated oncogenes (Gli) transcription factor families, the zincfinger transcription effectors $^{[15,16]}$. At least three members (Gli1, Gli2, and Gli3) 
of nuclear proteins Gli families have been identified in mammalian tissues ${ }^{[14,17]}$. Gli1 is a transcriptional activator ${ }^{[18]}$, which induces the expression of numerous target genes that regulates proliferation, differentiation, and extracellular matrix interactions ${ }^{[19,20]}$.

Increasing evidence has demonstrated that the Hh signaling pathway plays an important role in multiple tumor types, for example, basal cell carcinoma ${ }^{[21,22]}$, pancreatic cancer ${ }^{[23]}$, colon carcinoma $^{[24]}$, gastric cancer ${ }^{[25]}$, small cell lung cancer ${ }^{[26]}$, prostate cancer ${ }^{[27-29]}$, breast cancer ${ }^{[30,31]}$, early childhood hepatoblastoma $^{[32]}$, and esophageal cancers ${ }^{[33]}$.

Recent studies have revealed that the Hh signaling pathway is abnormally activated in human $\mathrm{HCC}^{[34-36]}$, and this pathway is thought to participate in the development of $\mathrm{HCC}^{[37-39]}$. Moreover, activation of the Hh pathway is correlated closely to invasion and metastasis of $\mathrm{HCC}^{[36,40]}$. Activated markers of the Hh signaling pathway such as Gli1 is significantly upregulated in the HCC tumor tissues ${ }^{[41]}$, and Gli inhibition can also suppress HCC tumor growth and metastases in vivo and in vitro ${ }^{[42]}$. However, the mechanism by which Hh signaling pathway is involved in HCC development is still unclear.

Hh signaling pathway can affect MAPK/ERK phosphorylation $^{[43]}$ and lead to carcinogenesis ${ }^{[44]}$. For example, it also can activate ERK1/2 in the breast epithelial cell ${ }^{[45]}$. However, other studies have revealed that in cancer the MAPK signaling pathway regulates $\mathrm{Hh}$ signaling, specifically Gli activity and expression $^{[46]}$. Therefore, what cellular mediators are involved in the crosstalk between the Hh signaling pathway and the MAPK signaling pathway in HCC? Now, there is no report about it.

Matrix metalloproteinase-9 (MMP-9 or gelatinase-B) is mostly associated with tumor migration, invasion and metastasis for various human cancers ${ }^{[10,47,48]}$. The Hh signaling pathway up-regulates cell migration and invasion in human gliomas and in pancreatic cancer by increasing the expressions of MMP-9 ${ }^{[49,50]}$. In addition, Smo and MMP-9 were overexpressed and associated with invasion and metastasis in HCC tissues ${ }^{[51]}$. Does the Hh signaling pathway mediate the migration and invasion of HCC by increasing the expressions of MMP-9? What is the correlation between MMP-9 and ERK pathway? However, they are incompletely understood in HCC.

In the present study, we investigated the mechanisms of the Hh signaling pathway in invasion and metastasis of HCC, specifically focused on the correlation between the Hh signaling pathway and the MAPK signaling pathway. Further we determined whether Hh signaling pathway involved in human HCC invasion and metastasis by up-regulating the expression of MMP-9 through ERK pathway.

\section{Materials and methods}

Patients and specimens

A total of 86 HCC patients, who had undergone liver resection without preoperative treatment at the First Affiliated Hospital of Anhui Medical University between June 2008 and December 2010, were examined. All tumor specimens were patho- logically diagnosed as HCC. Prior written informed consent was obtained from all patients according to the World Medical Association Declaration of Helsinki, and the study received ethics board approval from the Affiliated Hospital of Anhui Medical University. The age of patients ranged from 33 to 75 years, with an average age of 48.1 years. There were 68 males and 18 females, 50 I-II type- and 36 III-IV type-differentiated HCC, 37 patients with invasion and/or metastasis (Table 1).

\section{Reagents}

Dulbecco's modified Eagle's medium (DMEM) was obtained from Gbico Chemical Company (Gbico, USA). Shh and Gli1 antibodies were purchased from Santa Cruz Biotechnology Inc (Santa Cruz, CA, USA). p-ERK1/2 and MMP-9 antibodies were purchased from Abcam Biotechnology Inc (Abcam, UK). KAAD-cyclopamine(KAAD-cyc), Shh, U0126, and PD98059 were purchased from Toronto Research Chemicals (North York, Ontario, Canada) and Santa Cruz Biotechnology Inc (Santa Cruz, CA, USA). All chemicals were purchased in the purest form available.

\section{Cell line and culture conditions}

Human HCC cell line Bel-7402, obtained from the Shanghai Institute of Cell Biology, Chinese Academy of Sciences, was grown in DMEM supplemented with $10 \%$ heat-inactivated fetal bovine serum (FBS, Gbico, USA), $100 \mu \mathrm{g} / \mathrm{mL}$ streptomycin and $100 \mathrm{U} / \mathrm{mL}$ penicillin in a humidified atmosphere containing $5 \% \mathrm{CO}_{2}$ at $37^{\circ} \mathrm{C}$. Cells during exponential growth phase were used in the experiments. Cells were treated with KAAD-cyc, the special antagonist of Smo, Shh, U0126, or PD98059, control medium contained DMSO alone. In the invasion and metastasis experiments, cells were cultured in a serum-free medium.

\section{Immunohistochemistry staining}

Briefly, immunohistochemical stains were performed on formalin-fixed and paraffin-embedded tissue sections $(4 \mu \mathrm{m})$. The sections were prepared according to classical methods and treated with blocking solution before being sequentially incubated with primary antibodies against Shh (1:100), Gli1 (1:200), MMP-9 (1:100), and p-ERK1/2 (1:200) overnight at $4{ }^{\circ} \mathrm{C}$. The primary antibodies were visualized by incubating in a biotinylated antibody and HRP-conjugated streptavidin. Antigen staining was performed using diaminobenzidine then counterstained with hematoxylin. Negative controls were treated with the same species normal IgG in place of primary antibody. Images of each sample were taken and the percentage of positive cancer cells was quantified as the number of positive cells over the total number of cancer cells in that image. Expression was evaluated independently by two pathologists. Staining of sections was assessed in 10 consecutive fields (200× magnification) using a validated semiquantitative scale, which was indicated by both the percentage of positively stained tumor cells and the staining intensity. The percent positivity was scored as " 0 " ( $<5 \%$, negative), "1" (5\%-25\%, sporadic), " 2 " (25\%-50\%, focal), or “3” (>50\%, 
diffuse). The staining intensity was scored as " 0 " (no staining), "1" (weakly stained), "2" (moderately stained), or "3" (strongly stained). The immunostaining score was calculated as the percentage positive score $\times$ the staining intensity score. The expression levels were defined as follows: ' - ' (score 0-1), ' + ' (score 2-3), ' ++ ' (score 4-6), and ' +++ ' (score >6). The HCC patients were divided into the low expression group $(-$ or + ) and the high expression group $(++$ or +++$)$.

\section{Boyden chamber invasion assay}

The effect of KAAD-cyc, Shh, U0126, and PD98059 on HCC Bel-7402 was determined using Boyden chamber assay. Briefly, 24-well transwell units with polycarbonate membrane filters ( $8 \mu \mathrm{m}$ pore size, Costar, USA) were coated with $100 \mu \mathrm{L}$ matrigel (25 $\mu \mathrm{g}$ in $100 \mu \mathrm{L}$ PBS, Becton Dickinson), dried in a laminar hood overnight, and reconstituted in $100 \mu \mathrm{L}$, washed with phosphate-buffered saline (PBS) at $37^{\circ} \mathrm{C}$ for $2 \mathrm{~h}$, then PBS was discharged. Bel-7402 cells were resuspended in DMEM with $0.5 \%$ BSA $\left(5 \times 10^{4}\right.$ cells $\left./ 200 \mu \mathrm{L}\right)$ in the presence or absence of KAAD-cyc, Shh, U0126, or PD98059, which was added to the upper side of the invasion chamber. DMEM $(500 \mu \mathrm{L})$ with $2.5 \%$ FBS as chemoattractant was added to the lower chamber. After $24 \mathrm{~h}$, filter inserts were removed from the wells, the cells on the upper surface of the filter were wiped off using cotton swabs. The cells that penetrated to the lower surface were fixed with $4 \%$ paraformaldehyde, stained with $0.1 \%$ crystal violet in $20 \%$ ethanol, and counted in five randomly selected fields under phase contrast microscope. The invasion cells were monitored by photographing at $400 \times$ magnification with Olympus Microscope. The assay was performed in triplicate.

\section{Wound-healing assay}

Cell migration was examined using the wound-healing assay. Briefly, Bel-7402 cells were cultured to about $80 \%-90 \%$ confluence in a 6-well plate at $37^{\circ} \mathrm{C}$ and $5 \% \mathrm{CO}_{2}$. A wound about 1 $\mathrm{mm}$ width was created by scratching cells with a sterile $100 \mu \mathrm{L}$ micropipette tip. Cells were washed with PBS ( $\mathrm{pH}$ 6.8) three times to remove floating cells, then $1 \mathrm{~mL}$ serum-free DMEM was added. A computer-based microscopy imaging system was used to determine wound healing at $0 \mathrm{~h}$ with a microscope at $200 \times$ magnification. Then $1 \mathrm{~mL}$ serum-free DMEM was added with different concentrations of KAAD-cyc, Shh, U0126, or PD98059. After $24 \mathrm{~h}$, photoes of the wound were taken under $200 \times$ magnification. The values of wound-healing were assessed by measuring the pixel of wound area by Photoshop 7.01 software. The experiments were performed in triplicate.

\section{Western blots analysis}

Cells were plated onto culture flask at a density of $2 \times 10^{5}$ cells $/ \mathrm{mL}$, cultured at $37^{\circ} \mathrm{C}$ and $5 \% \mathrm{CO}_{2}$. The next day, different concentrations of KAAD-cyc, Shh, U0126, or PD98059 were added. After $24 \mathrm{~h}$, the levels of Shh, Gli1, MMP-9, p-ERK1/2 proteins were quantified through Western blots. The proteins were extracted through the addition of $200 \mu \mathrm{L}$ of lysis buffer ( $1 \mathrm{mmol} / \mathrm{L}$ EDTA, $1.5 \mathrm{mmol} / \mathrm{L} \mathrm{MgCl}_{2}, 150 \mathrm{mmol} / \mathrm{L} \mathrm{NaCl}, 50$
mmol/L Hepes, $50 \mu \mathrm{mol} / \mathrm{L}$ DTT, $1 \mathrm{mmol} / \mathrm{L}$ phenylmethylsulfonyl fluoride and $10 \mathrm{mg} / \mathrm{mL}$ leupeptin, $\mathrm{pH}$ 7.4) to each well. The cell lysates were incubated on ice for $30 \mathrm{~min}$ vortexing every $10 \mathrm{~min}$, followed by centrifugation at $12000 \times \mathrm{g}$ for $30 \mathrm{~min}$ at $4{ }^{\circ} \mathrm{C}, 50 \mu \mathrm{g} / \mu \mathrm{L}$ protein of cell lysate was mixed equally with $2 \times$ electrophoresis buffer [50\% glycerol, 25\% mercaptoethanol, $10 \%$ SDS, $0.3 \mathrm{~mol} / \mathrm{L}$ Tris ( $\mathrm{pH} 6.8$ ), $0.025 \%$ bromophenol blue] and boiled for $10 \mathrm{~min}$. The samples (50 $\mathrm{g}$ of protein) of total cell lysates were separated by sodium dodecyl sulfate-polyacrylamide gel electrophoresis and electrophoretically transferred onto a polyvinylidene difluoride membrane (Millipore) in transfer buffer containing $25 \mathrm{mmol} / \mathrm{L}$ Tris, $150 \mathrm{mmol} / \mathrm{L}$ glycine and 20\% methanol. The membranes were blocked using 5\% BSA (pH 7.4, 0.5\% Tween 20). The membranes were incubated with primary antibodies, anti-MMP-9 (1:1000), antip-ERK1/2 (1:500) and anti-Gli1 (1:500) for $16-18 \mathrm{~h}$ at $4{ }^{\circ} \mathrm{C}$. The membranes were subsequently probed with anti-mouse or anti-rabbit IgG antibodies (1:5000) with the HRP for $1 \mathrm{~h}$. Control blots were performed using anti-actin antibody (1:500, Santa Cruz, CA, USA). The membranes were washed in PBS for $30 \mathrm{~min}$ at room temperature, and detection was achieved by measuring the chemiluminescence of the blotting agent after exposure of the filters on films. At last, the densities of the bands were quantified with a computerized densitometer (Image J Launcher, Broken Symmetry Software).

\section{Statistical analysis}

Statistical analyses were performed using the SPSS 11.0 software program (SPSS Software Products, Chicago, IL, USA). All data were presented as number or mean \pm standard deviation (SD). Associations between protein expression and clinicopathologic variables were analyzed by ChiSquare Test. Statistical analysis among more groups was performed by oneway analysis of variance (ANOVA). The Spearman coefficient of correlation was used to examine the correlation. Statistical significance of differences were accepted at $P<0.05$.

\section{Results}

Overexpression of Shh, Gli1, p-ERK1/2, and MMP-9 in HCC liver tissues with invasion and metastasis compared with nonmetastasis HCC liver tissue

We detected Shh, Gli1 MMP-9, and p-ERK1/2 expressions in 86 cases of HCC liver tissues with or without invasion and metastasis by IHC staining. We further evaluated the relationships between Gli1 and p-ERK1/2, Gli1 and MMP-9 on invasion and metastasis of HCC. The results indicated Shh, Gli1, p-ERK1/2, and MMP-9 expressions had no notable relationship with age and tumor diameter. However, Gli1, p-ERK1/2, and MMP-9 expressions had a significant correlation with the pathological grade and metastasis of the tumor sample (Table 1). Positive expressions of Shh, p-ERK1/2, and MMP-9 were remarkably stronger in HCC liver tissues with metastasis than in non-metastasis HCC liver tissues. A significant difference was observed in expression of Gli1 in the nucleus between HCC tissues with metastasis and non-metastatic HCC liver tissue $(91.89 \%$ vs $36.74 \%, P<0.01$, Figure 1$)$. Interestingly, 
Table 1. Relationship between expression of Shh, Gli1, p-ERK1/2, and MMP-9 and clinical features of HCC ( $n=86$ ).

\begin{tabular}{|c|c|c|c|c|c|c|}
\hline Clinical parameter & $\begin{array}{c}\text { Cases } \\
(n)\end{array}$ & $\begin{array}{c}\text { Shh } \\
(\exp -\mathrm{h} / \exp -1)\end{array}$ & $\begin{array}{l}\text { Gli1 (nuclei) } \\
\text { (exp-h/exp-l) }\end{array}$ & $\begin{array}{l}\mathrm{p}-\mathrm{ERK} 1 / 2 \\
(\exp -\mathrm{h} / \exp -\mathrm{l})\end{array}$ & $\begin{array}{c}\text { MMP-9 } \\
(\text { exp-h/exp-I) }\end{array}$ & $\begin{array}{c}P \text { value } \\
\text { (Shh, Gli1, p-ERK1/2, MMP-9) }\end{array}$ \\
\hline \multicolumn{7}{|l|}{ Age (year) } \\
\hline$>50$ & 40 & $31 / 9$ & $25 / 15$ & $23 / 17$ & $24 / 16$ & $0.1041,0.8902,0.3493,0.6264$ \\
\hline$\leq 50$ & 46 & $27 / 19$ & $27 / 19$ & $32 / 14$ & $31 / 15$ & \\
\hline \multicolumn{7}{|c|}{ Tumor diameter $(\mathrm{cm})$} \\
\hline$\leq 3$ & 19 & $16 / 3$ & $16 / 3$ & $10 / 9$ & $13 / 6$ & \\
\hline \multicolumn{7}{|l|}{ Pathological grade } \\
\hline I-II & 50 & $27 / 23$ & $25 / 25$ & $27 / 23$ & $29 / 21$ & $0.0041,0.0342,0.0423,0.2604$ \\
\hline III-IV & 36 & $31 / 5$ & $27 / 9$ & $28 / 8$ & $26 / 10$ & \\
\hline \multicolumn{7}{|c|}{ Invasion or metastasis } \\
\hline
\end{tabular}

Abbreviations: exp-h, high expression; exp-l, low expression.
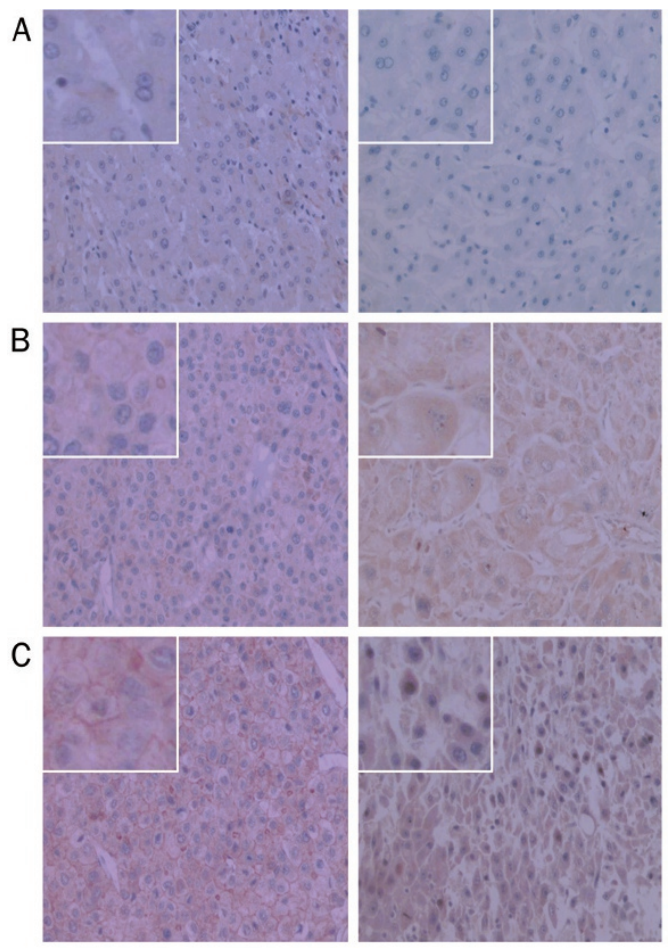

Shh

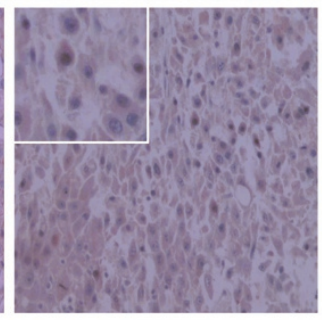

Gli1
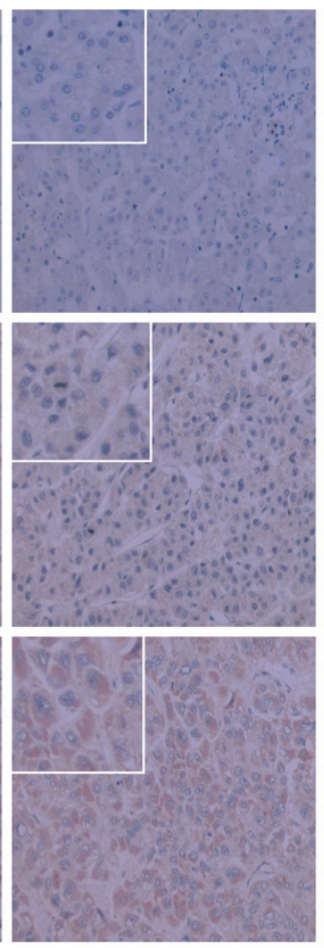

p-ERK1/2
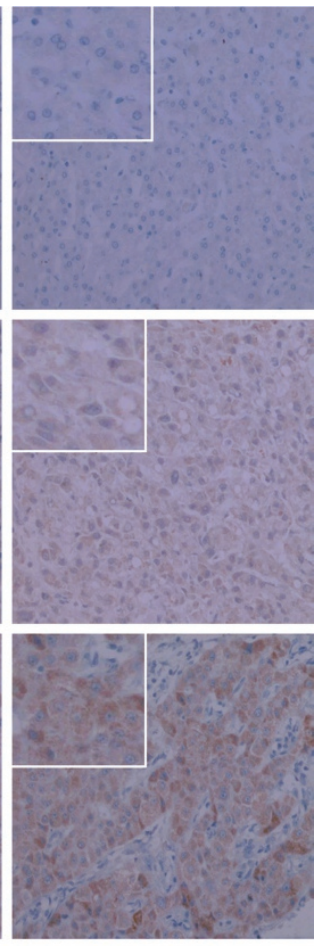

MMP-9
Figure 1. Results of $\mathrm{IHC}$ staining for Shh, Gli1, p-ERK1/2, and MMP-9 from 86 HCC liver tissues including 37 cases with metastasis at $200 \times$ magnification. Representative images are displayed. Expression of Shh was defined as the cytoplasmic and plasmalemmal staining. Expression of MMP-9 was defined as cytoplasmic staining. Gli1, and p-ERK1/2 were located in cytoplasm and/or nucleus. (A) Normal liver tissues; (B) Nonmetastatic HCC liver tissues; (C) Metastatic HCC liver tissues. expression of Gli1 was also notably correlated to expressions of MMP-9 and p-ERK1/2 ( $<<0.01$, Table 1$)$. Those results suggested that Hh signal pathway mediated invasion and metastasis of human HCC by up-regulating the protein expression MMP-9 and p-ERK1/2.

KAAD-cyc inhibited the invasion and migration of Bel-7402 cells

Bel-7402 cell invasion and motility were investigated using a
Boyden chamber invasion assay and wound-healing assay, respectively. KAAD-cyc is a specific inhibitor of the Hh signaling pathway and was utilized to determine the effect of this pathway on invasion and metastasis in Bel-7402 cells. The results indicated KAAD-cyc notably inhibited migration of Bel-7402 cells on the surface of the tissue culture plate, significantly decreased area of wound-healing by $45.87 \%$ at most compared with controls in the wound-healing assay. 
Meanwhile, KAAD-cyc significantly decreased the numbers of cells to the lower chamber when the cells were treated with 1 $\mu \mathrm{mol} / \mathrm{L}$ and $4 \mu \mathrm{mol} / \mathrm{L}$ of KAAD-cyc for $24 \mathrm{~h}$ in Boyden chamber invasion assay, inhibitory rates were $43.50 \% \pm 15.41 \%$ and $56.36 \% \pm 15.17 \%$, respectively. Collectively, these data demonstrated that KAAD-cyc could suppress the invasion and metastasis of Bel-7402 cells (Figure 2).
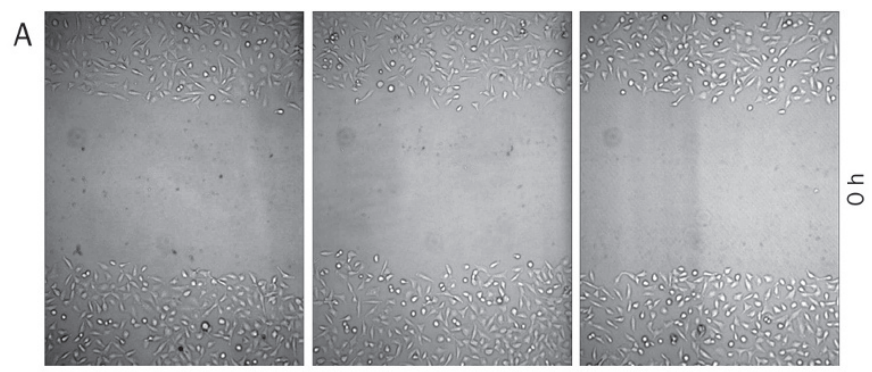

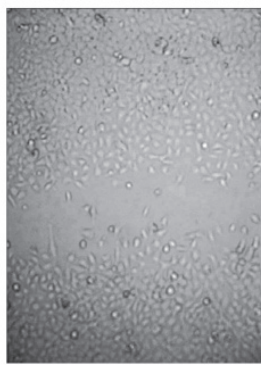

0

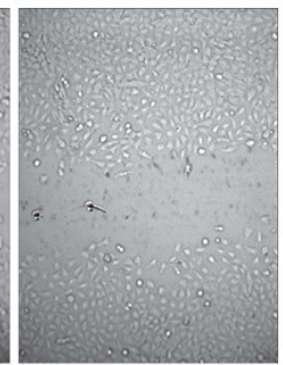

1

KAAD-cyc ( $\mu \mathrm{mol} / \mathrm{L})$

\section{B}

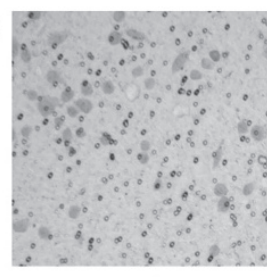

0

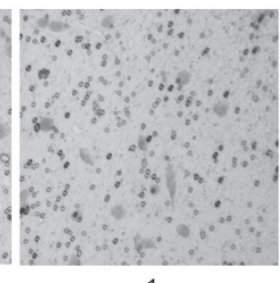

1

KAAD-cyc $(\mu \mathrm{mol} / \mathrm{L})$
C

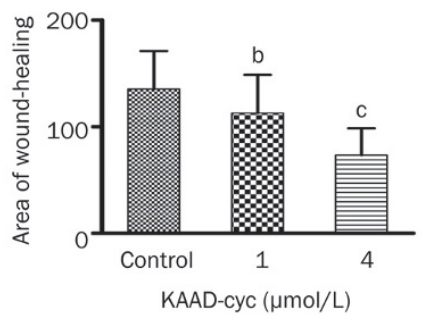

D

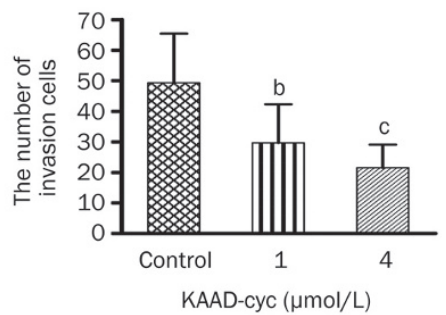

Figure 2. KAAD-cyc inhibits the invasion and migration of Bel-7402 cells. (A) Representative photographs (200×magnification) of cells treated with and without KAAD-cyc for $24 \mathrm{~h}$ after wounding from a representative experiment. (B) Representative photographs (400×magnification) of Bel7402 cells treated with and without KAAD-cyc for $24 \mathrm{~h}$ in the invasion assay from 1 of 3 independent experiments. (C) Values of wound-healing assessed by measuring the pixel of wound-healing area. (D) The number of Bel-7402 cells in the lower chamber. Mean \pm SD. $n=3 .{ }^{b} P<0.05$, ${ }^{\mathrm{c}} \mathrm{P}<0.01$ vs control.

\section{Shh increased invasion and migration of Bel-7402 cells}

As illustrated in Figure 3, Shh notably improved the migration of Bel-7402 cells, significantly increased area of woundhealing by greater than $41.63 \%$. At the same time, Shh could significantly increase the number of migrating Bel-7402 cells in the lower chamber when the cells were treated with 0.13 $\mu \mathrm{g} / \mathrm{mL}$ and $0.5 \mu \mathrm{g} / \mathrm{mL}$ Shh for $24 \mathrm{~h}$, incremental rates were $49.99 \% \pm 14.04 \%$ with $0.13 \mu \mathrm{g} / \mathrm{mL}$ Shh and $69.28 \% \pm 20.29 \%$ with $0.5 \mu \mathrm{g} / \mathrm{mL}$ Shh in invasion assays. Those data demonstrated
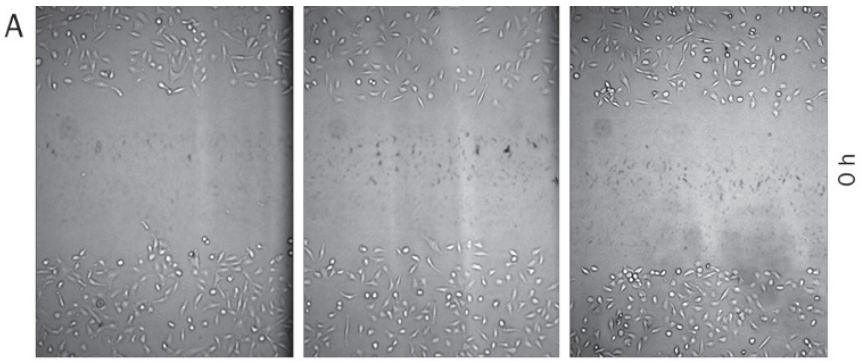

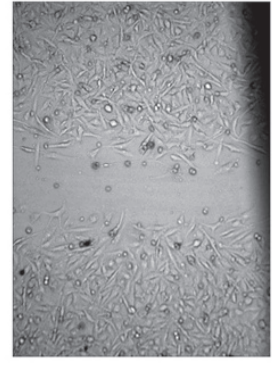

0

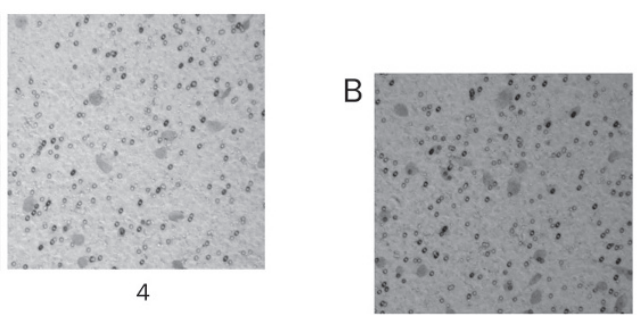

0

C

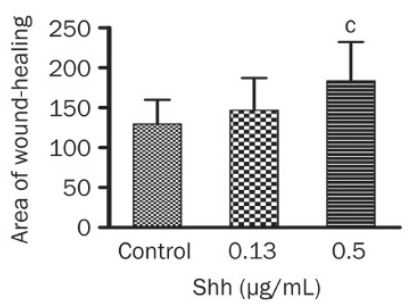

Figure 3. Shh increases invasion and migration of Bel-7402 cells. (A) Representative photographs (200×magnification) of metastatic cells treated with and without Shh $24 \mathrm{~h}$ after wounding from a representative experiment. (B) Representative photographs (400×magnification) of Bel7402 cells treated with or without Shh for $24 \mathrm{~h}$ in invasion assay from 1 of 3 independent experiments. (C) Values of wound-healing assessed by measuring the pixel of wound area. (D) The numbers of Bel-7402 cells in the lower chamber. Mean \pm SD. $n=3 .{ }^{b} P<0.05,{ }^{c} P<0.01$ vs control. 
that Shh greatly enhanced the invasive and migratory capacity of Bel-7402 cells.

\section{U0126 and PD98059 inhibited invasion and migration of} Bel-7402 cells induced by Shh

Hh signaling pathway can lead to carcinogenesis via activation of ERK1/2. Therefore we determined whether the Hh signaling pathway promotes invasion and migration of Bel-7402 cells through p-ERK1/2. The MAPK inhibitor, U0126 and PD98059, were used in the invasion and migration assays with Bel-7402 cells in vitro. The results indicated that Shh notably increased the invasion and migration of Bel-7402 cells $(P<0.01)$. U0126 significantly decrease the numbers of migratory Bel-7402 cells elevated by Shh. The inhibitory rates were $61.72 \% \pm 18.75 \%$ with $5 \mu \mathrm{mol} / \mathrm{L}$ U0126 and $117.63 \% \pm 28.90 \%$ with $10 \mu \mathrm{mol} / \mathrm{L}$ U0126. At the same time, U0126 notably inhibited migration of Bel-7402 cells induced by Shh, significantly decreased area of wound-healing by greater than $86.87 \%$ (Figure 4). PD98059 had similar effects with U0126 on the invasion and migration of Bel-7402 cells induced by Shh. These studies demonstrated that the U0126 and PD98059 could suppress the invasion and migration capacity of Bel-7402 cells induced by Shh.

Effects of KAAD-cyc on the expression of Gli1, p-ERK1/2, and MMP-9 proteins in Bel-7402 cells

Bel-7402 cells were cultured in serum-free media containing 1 and $4 \mu \mathrm{mol} / \mathrm{L} \mathrm{KAAD-cyc}$ for $24 \mathrm{~h}$. The expression of Gli1, p-ERK1/2, and MMP-9 proteins were determined by Western blot analysis. The results indicated that KAAD-cyc dramatically inhibited the expression of Gli1, p-ERK1/2, and MMP-9 proteins in Bel-7402 compared with vehicle control (Figure 5A and $5 \mathrm{~B})$.

\section{Effects of Shh on the expression of Gli1, p-ERK1/2, and MMP-9} proteins in Bel-7402 cells

Bel-7402 cells were cultured in serum-free media containing 0.13 and $0.50 \mathrm{\mu g} / \mathrm{mL}$ Shh for $24 \mathrm{~h}$. The expression of Gli1, p-ERK1/2, and MMP-9 proteins were determined by Western blot analysis. The results indicated that Shh dramatically increased the expression of Gli1, p-ERK1/2, and MMP-9 in
A

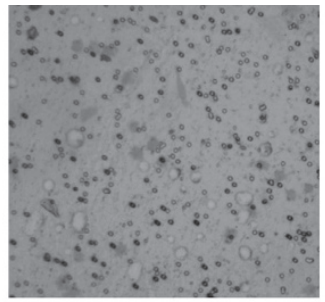

B

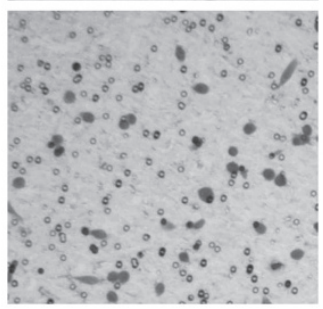

$\operatorname{Shh}(\mu \mathrm{g} / \mathrm{mL})$ U0126/PD98059 $(\mu \mathrm{mol} / \mathrm{L})$

C

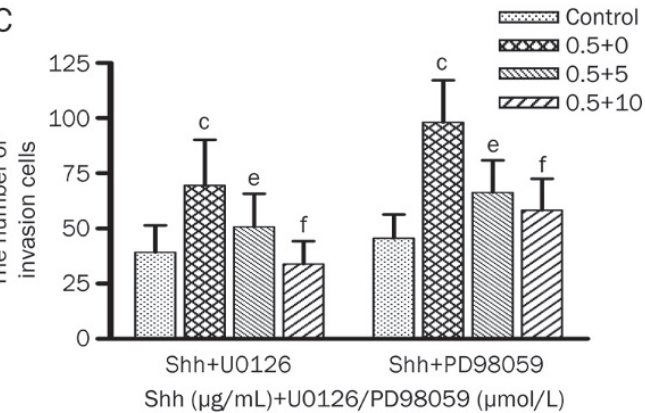

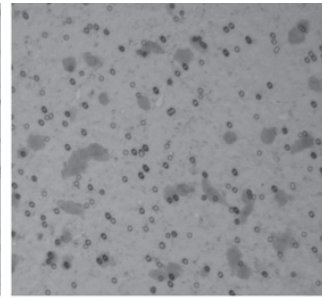
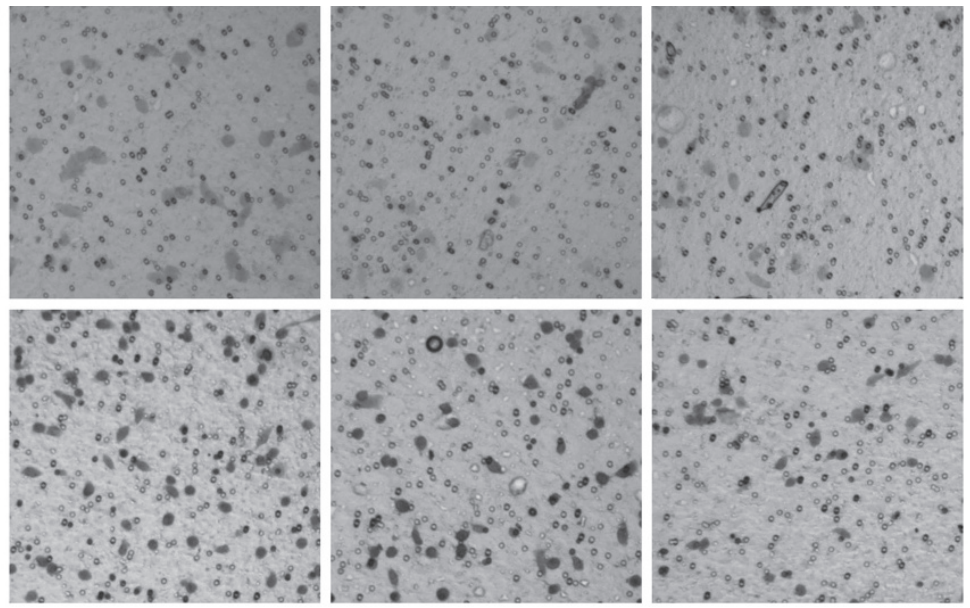

0.5

5

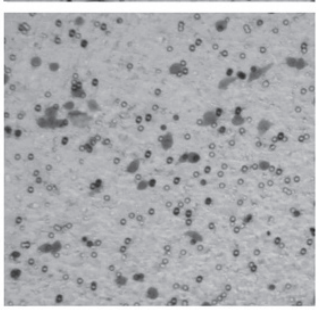

0.5

10

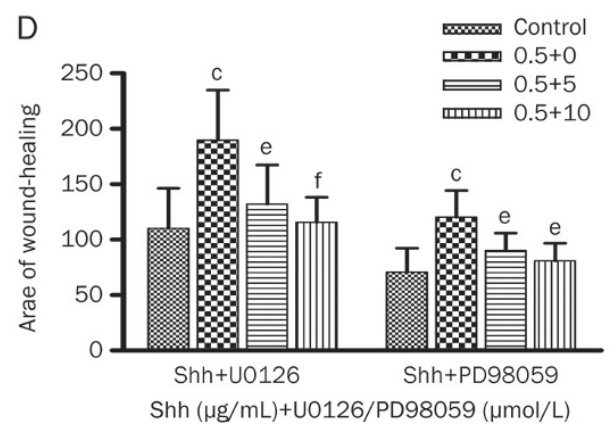

Figure 4. U0126 and PD98059 inhibit invasion and migration of Bel-7402 cells induced by Shh. (A) Representative photographs (400×magnification) of Bel- 7402 cells treated with or without $U 0126$ for $24 \mathrm{~h}$ after being pretreated by Shh from a representative experiment. (B) Representative photographs (400×magnification) of Bel-7402 cells treated with or without PD98059 for $24 \mathrm{~h}$ after being pretreated by Shh from a representative experiment. (C) The numbers of Bel-7402 cells in the lower chamber in Figure 4A and 4B, each bar represents the mean \pm SD of three separate experiments. (D) Values of wound-healing assessed by measuring the pixel of wound area, each bar represents the mean \pm SD of three separate experiments. ${ }^{b} P<0.05,{ }^{\circ} P<0.01$ vs control; ${ }^{\mathrm{e}} P<0.05,{ }^{\mathrm{f}} P<0.01$ vs Shh. 

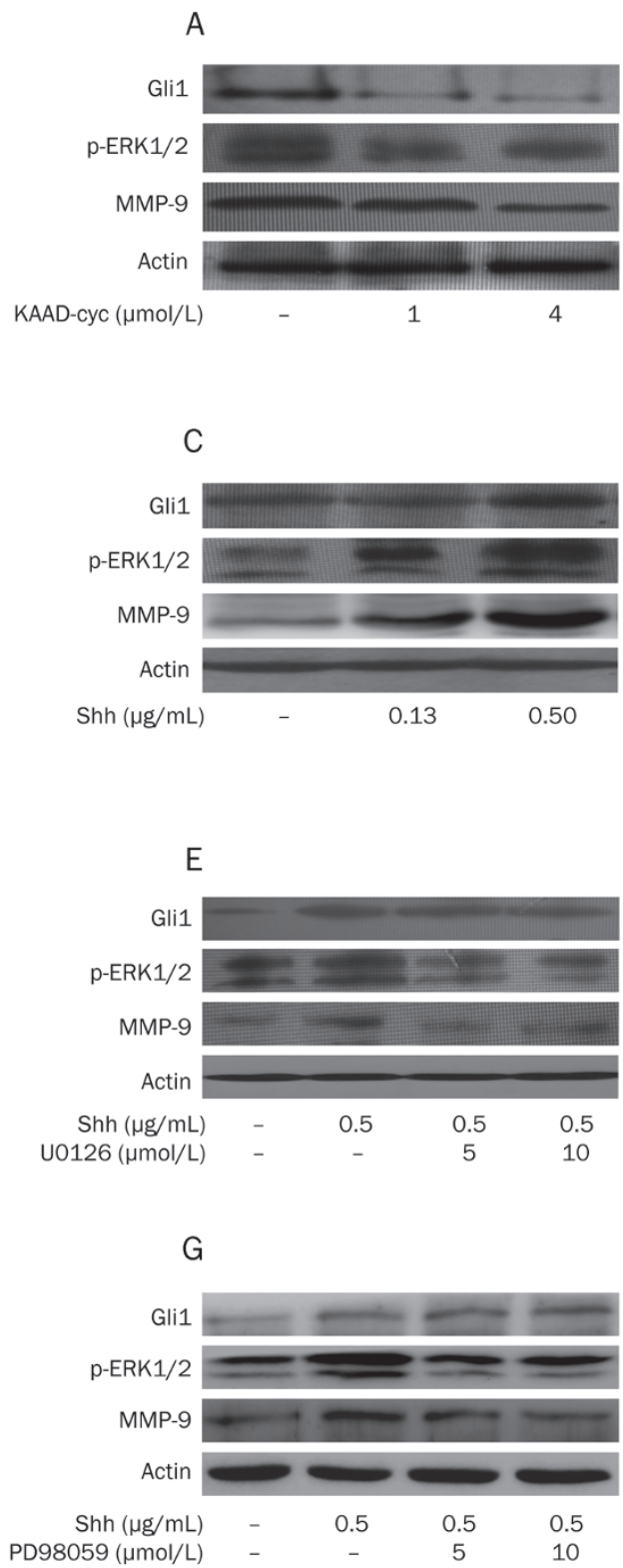
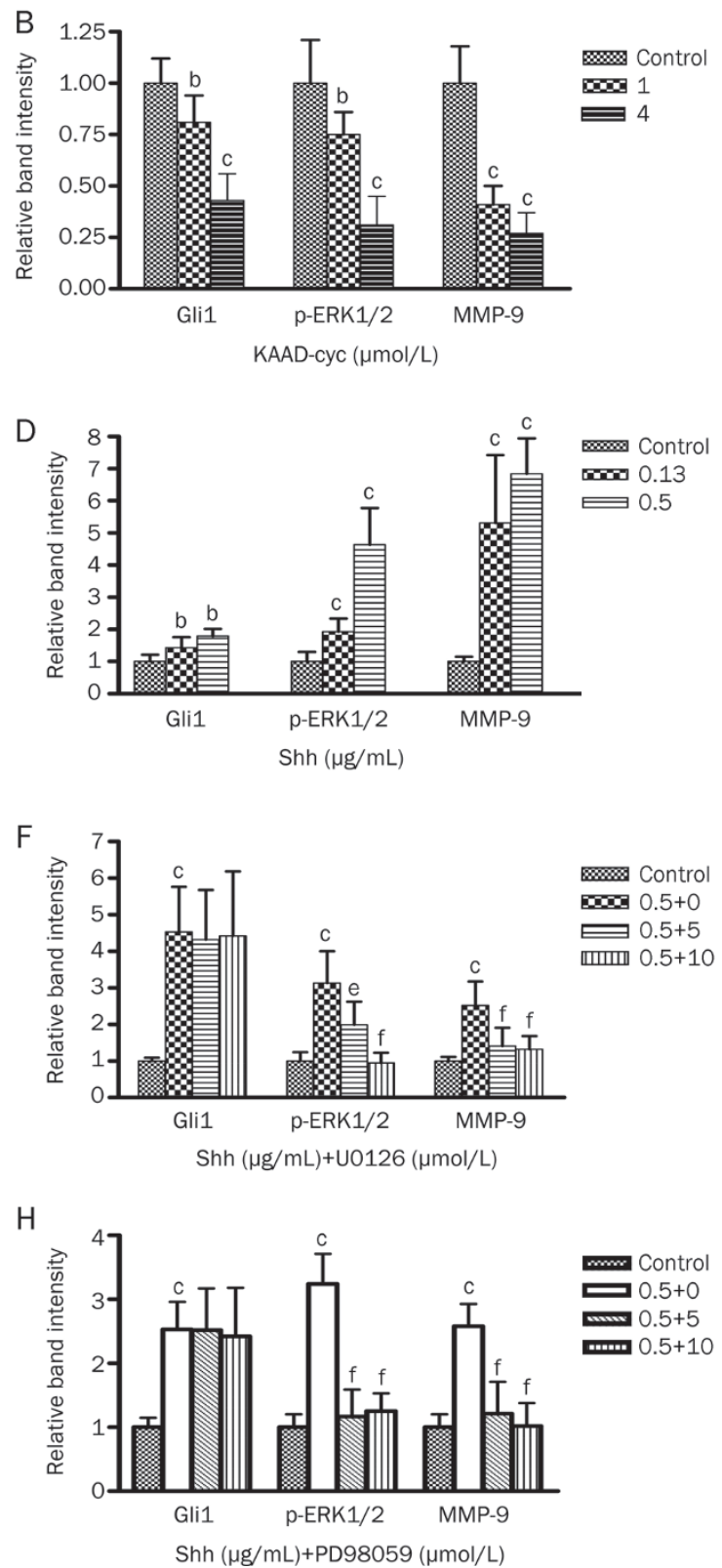

Figure 5. Effects of KAAD-cyc, Shh, U0126, or PD98059 on the expressions of Gli1, p-ERK1/2, and MMP-9 proteins in Bel-7402 cells. (A) Western blot analysis of Gli1, p-ERK1/2, and MMP-9 protein levels in cell lysates from Bel-7402 cells treated with 1 or $4 \mu$ mol/L KAAD-cyc for $24 \mathrm{~h}$. (B) The values under each lane indicate relative density of the band in Figure 5A normalized to $\beta$-actin, respectively. (C) Western blot analysis of Gli1, p-ERK1/2, and MMP-9 protein levels in cell lysates from Bel-7402 cells treated with 0.13 or $0.50 \mu \mathrm{g} / \mathrm{mL}$ Shh for $24 \mathrm{~h}$. (D) The values under each lane indicate relative density of the band in Figure $5 \mathrm{C}$ normalized to $\beta$-actin, respectively. (E) Western blot analysis of Gli1, p-ERK1/2, and MMP-9 protein levels in cell lysates from Bel-7402 cells pretreated by $0.50 \mu \mathrm{g} / \mathrm{mL}$ Shh, then treated with 5 or $10 \mu \mathrm{mol} / \mathrm{L}$ U0126 for $24 \mathrm{~h}$. (F) The values under each lane indicate relative density of the band in Figure 5E normalized to $\beta$-actin, respectively. (G) Western blot analysis of Gli1, p-ERK1/2, and MMP-9 protein levels in cell lysates from Bel-7402 cells pretreated by $0.50 \mu \mathrm{g} / \mathrm{mL}$ Shh, then treated with 5 or $10 \mu \mathrm{mol} / \mathrm{L}$ PD98059 for $24 \mathrm{~h}$. (H) The values under each lane indicate relative density of the band in Figure $5 \mathrm{G}$ normalized to $\beta$-actin, respectively. ${ }^{\mathrm{b}} P<0.05,{ }^{\mathrm{c}} P<0.01$ vs control; ${ }^{\mathrm{e}} P<0.05,{ }^{\mathrm{f}} P<0.01$ vs $\mathrm{Shh}$.

Bel-7402 in concentration dependent manner compared with vehicle control (Figure 5C and 5D).

Effects of U0126 and PD98059 on the expression of Gli1, p-ERK1/2, and MMP-9 in Bel-7402 cells induced by Shh

After Bel-7402 cells were treated with $0.5 \mu \mathrm{g} / \mathrm{mL}$ Shh, then 5 or $10 \mu \mathrm{mol} / \mathrm{L}$ U0126 and 5 or $10 \mu \mathrm{mol} / \mathrm{L}$ PD98059 were added for $24 \mathrm{~h}$. Western blot analysis indicated that both U0126 and PD98059 dramatically inhibited the expression of MMP-9 and p-ERK1/2 in a concentration dependent manner. However, both U0126 and PD98059 had no effects on expression of Gli1 under the same condition compared with vehicle control (Fig- 
ure $5 \mathrm{E}$ and $5 \mathrm{G})$.

\section{Discussion}

Hepatocellular carcinoma (HCC) is one of the most malignant cancers especially in Asian countries, and its poor prognosis is mainly due to metastasis after excision ${ }^{[52]}$. Currently there are no available effective treatment ${ }^{[53,54]}$. Studies of the underlying molecular mechanism of HCC metastasis provide potential to identify new therapeutic targets. Previous evidence has demonstrated that the Hh signaling plays an important role in multiple tumor types. This signaling pathway is involved in and participates development, invasion and metastasis of $\mathrm{HCC}^{[34-40]}$. In this study, we further detected expression of Shh and Gli1 in metastasis and non-metastasis HCC liver tissues, simultaneously we used KAAD-cyc, a specific inhibitor of $\mathrm{Hh}$ pathway and Shh, a ligand of the Hh pathway in invasion and metastasis assays of human HCC cell line, and we confirmed the results. However, to date no report has been presented to identify a potential mechanism. Therefore we investigated the mechanisms of the Hh signaling pathway in HCC invasion and metastasis. Gli1, a transcription factor activated in the $\mathrm{Hh}$ pathway, significantly enhanced tumor growth and metastases of other cancers through the activation of ERK1/2 $2^{[22,45]}$. Overexpression of MMP-9 is also a key factor for tumor invasion and metastasis ${ }^{[47,48,55]}$. Moreover, the Hh signaling pathway may enhance migration and invasion of cancer cells by increasing the expression of MMP- $9^{[49,50]}$.

In the present study, we found that expressions of Shh, MMP-9, and p-ERK1/2 were remarkably stronger in HCC samples with metastasis than in non-metastasis HCC liver samples. Moreover, there was a significant difference in expression of Gli1 in nuclei of cells in HCC tissue samples with metastasis compared to and HCC samples with no metastasis. Moreover, expression of Gli1 was also positively correlated to expressions of both MMP-9 and p-ERK1/2. These data suggested that the Hh signal pathway may be involved in human HCC invasion and metastasis by up-regulating the protein expression MMP-9 and p-ERK1/2.

Since the Hh signaling pathway has been associated with MAPK/ERK pathway in different cancer ${ }^{[43-46]}$, furthermore our results indicate that the pathway is also notably correlated to expressions of p-ERK1/2 in HCC tissues. To confirm these results, we treated a HCC cell line, Bel-7402 cells, with KAAD-cyc, Shh, U0126, or PD98059 in vitro. Our results demonstrated that KAAD-cyc inhibited the invasion and migration of Bel-7402 cells and decreased the expression of Gli1, p-ERK1/2 proteins in Bel-7402, but Shh increased the expression of Gli1, p-ERK1/2 proteins. U0126 and PD98059 inhibited the invasion and metastasis of Bel-7402 cells induced by Shh, decreased the expression of Gli1 proteins, but they had no effect on the expression of Gli1. These indicate that the Hh signal pathway is involved in human HCC invasion and metastasis by up-regulating the expression of MAPK/ ERK pathway, instead of the MAPK/ERK pathway inducing expression of Gli1.

Matrix metalloproteinases (MMPs) have long been associ- ated with cancer cell invasion and metastasis. MMPs are proteolytic enzymes, their basic mechanism of action is to degrade proteins in extracellular matrix. Activation of MMPs has been detected in almost all type of human cancers, which is closely correlated to advanced tumor stage, increasing tumor invasion and metastasis. Onishi et al reported that the Hh signaling pathway up-regulated cell migration and invasion in human cancers by increasing expressions of MMP- $9^{[50]}$. However, the relationship among the Hh signaling pathway, MAPK/ERK pathway and MMP-9 remains unclear. Our results indicate that the Hh pathway is also correlated with expressions of p-ERK1/2 and MMP-9 in HCC tissues. In Bel-7402 cellular assays, KAAD-cyc inhibited expression of MMP-9 proteins, and Shh up-regulated expression of MMP-9 proteins. Both U0126 and PD98059 were able to inhibit the expression of MMP-9 elevated by Shh. Therefore, we concluded that the Hh signaling pathway mediated the protein expression MMP-9 through MAPK/ERK pathway.

Most importantly, we have confirmed that the Hh signal pathway is involved in human HCC invasion and metastasis. We hypothesize and also deduce that the Hh signaling pathway activates the ERK pathway, subsequently, the ERK pathway up-regulates the protein expression of MMP-9, thereby mediating human HCC invasion and metastasis. These data may assist in identifying novel diagnostic markers and therapeutic targets for the treatment of highly aggressive HCC.

\section{Acknowledgements}

The study is supported by National Natural Science Foundation of China (№ 30973543 and 81173075), and Anhui Provincial Natural Science Foundation (№_090413108 and KJ2012A160).

The authors thank senior technician Cheng-yi WU, Ai-wu ZHOU and Yun-fang ZHANG, technician Li-hua LIU for their excellent technical assistance.

\section{Author contribution}

Wei WEI and Jing-tao LU designed the research; Jing-tao LU, Wen-di ZHAO, and Wei HE performed the research; Jingtao LU and Wei HE analyzed data; and Jing-tao LU wrote the paper.

\section{Abbreviations}

HCC, hepatocellular carcinoma; Hh, hedgehog; PI3K, phosphatidylinositol-3 kinase; Ptc, patched; Smo, smoothened; Gli, the glioma-associated oncogenes; KAAD-cyc, KAAD-cyclopamine; MMPs, matrix metalloproteinases; PBS, phosphate-buffered saline; DMEM, Dulbecco's modified Eagle's medium.

\section{References}

1 Aravalli RN, Steer CJ, Cressman EN. Molecular mechanisms of hepatocellular carcinoma. Hepatology 2008; 48: 2047-63.

2 Walzer N, Kulik LM. Hepatocellular carcinoma: latest developments. Curr Opin Gastroenterol 2008; 24: 312-9.

3 Parkin DM, Bray F, Ferlay J, Pisani P. Global cancer statistics, 2002. 
CA Cancer J Clin 2005; 55: 74-108.

4 Chen XP, Qiu FZ, Wu ZD, Zhang ZW, Huang ZY, Chen YF, et al. Effects of location and extension of portal vein tumor thrombus on long-term outcomes of surgical treatment for hepatocellular carcinoma. Ann Surg Oncol 2006; 13: 940-6.

5 Tang ZY, Ye SL, Liu YK, Qin LX, Sun HC, Ye QH, et al. A decade's studies on metastasis of hepatocellular carcinoma. J Cancer Res Clin Oncol 2004; 130: 187-96.

6 Min L, He B, Hui L. Mitogen-activated protein kinases in hepatocellular carcinoma development. Semin Cancer Biol 2011; 21: 1020.

7 Hsieh YH, Wu TT, Huang CY, Hsieh YS, Hwang JM, Liu JY. p38 mitogenactivated protein kinase pathway is involved in protein kinase Calpharegulated invasion in human hepatocellular carcinoma cells. Cancer Res 2007; 67: 4320-7.

8 Martínez-López N, Varela-Rey M, Fernández-Ramos D, Woodhoo A, Vázquez-Chantada M, Embade N, et al. Activation of LKB1-Akt pathway independent of phosphoinositide 3-kinase plays a critical role in the proliferation of hepatocellular carcinoma from nonalcoholic steatohepatitis. Hepatology 2010; 52: 1621-31.

9 Whittaker S, Marais R, Zhu AX. The role of signaling pathways in the development and treatment of hepatocellular carcinoma. Oncogene 2010; 29: 4989-5005.

10 Chen JS, Wang Q, Fu XH, Huang XH, Chen XL, Cao LQ, et al. Involvement of PI3K/PTEN/AKT/mTOR pathway in invasion and metastasis in hepatocellular carcinoma: Association with MMP-9. Hepatol Res 2009; 39: 177-86.

11 Wei W, Chua MS, Grepper S, So SK. Blockade of Wnt-1 signaling leads to anti-tumor effects in hepatocellular carcinoma cells. Mol Cancer 2009; 8: 76-81.

12 Kaposi-Novak P, Lee JS, Gòmez-Quiroz L, Coulouarn C, Factor VM, Thorgeirsson SS. Met-regulated expression signature defines a subset of human hepatocellular carcinomas with poor prognosis and aggressive phenotype. J Clin Invest 2006; 116: 1582-95.

13 Horiguchi N, Takayama H, Toyoda M, Otsuka T, Fukusato T, Merlino $\mathrm{G}$, et al. Hepatocyte growth factor promotes hepatocarcinogenesis through c-Met autocrine activation and enhanced angiogenesis in transgenic mice treated with diethylnitrosamine. Oncogene 2002; 21: 1791-9.

14 Ruizi AA, Sanchez P, Dahmane N. Gli and hedgehog in cancer: tumours, embryos and stem cells. Nat Rev Cancer 2002; 2: 361-72.

15 Goetz JA, Suber LM, Zeng X, Robbins DJ. Sonic hedgehog as a mediator of long-range signaling. Bioessays 2002; 24: 157-65.

16 Nybakken K, Perrimon N. Hedgehog signal transduction: recent findings. Curr Opin Genet Dev 2002; 12: 503-11.

17 Sasaki H, Nishizaki Y, Hui C, Nakafuku M, Kondoh H. Regulation of Gli2 and Gli3 activities by an amino-terminal repression domain: implication of Gli2 and Gli3 as primary mediators of Shh signaling. Development 1999; 126: 3915-24.

18 Stepan V, Ramamoorthy S, Nitsche H, Zavros Y, Merchant JL, Todisco A. Regulation and function of the sonic hedgehog signal transduction pathway in isolated gastric parietal cells. J Biol Chem 2005; 280 : 15700-8.

19 Ingham PW, McMahon AP. Hedgehog signaling in animal development: paradigms and principles. Genes Dev 2001; 15: 3059-87.

20 Cohen MM Jr. The Hedgehog signaling network. Am J Med Genet 2003; 123A: 5-28.

21 Kump E, Ji J, Wernli M, Häusermann P, Erb P. Gli2 upregulates cFlip and renders basal cell carcinoma cells resistant to death ligandmediated apoptosis. Oncogene 2008; 27: 3856-64.

22 Caro I, Low JA. The role of the hedgehog signaling pathway in the development of basal cell carcinoma and opportunities for treatment. Clin Cancer Res 2010; 16: 3335-9.

23 Bisht S, Brossart P, Maitra A, Feldmann G. Agents targeting the Hedgehog pathway for pancreatic cancer treatment. Curr Opin Investig Drugs 2010; 11: 1387-98.

24 Yoshikawa K, Shimada M, Miyamoto H, Higashijima J, Miyatani T, Nishioka $M$, et al. Sonic hedgehog relates to colorectal carcinogenesis. J Gastroenterol 2009; 44: 1113-7.

25 Katoh Y, Katoh M. Hedgehog signaling pathway and gastric cancer. Cancer Biol Ther 2005; 4: 1050-4.

26 Velcheti V, Govindan R. Hedgehog signaling pathway and lung cancer. J Thorac Oncol 2007; 2: 7-10.

27 Thayer SP, di Magliano MP, Heiser PW, Nielsen CM, Roberts DJ, Lauwers GY, et al. Hedgehog is an early and late mediator of pancreatic cancer tumorigenesis. Nature 2003; 425: 851-6.

28 Reagan-Shaw S, Cozma D, Thomas-Tikhonenko A, Ahmad N, Spiegelman VS. Role of GLI2 transcription factor in growth and tumorigenicity of prostate cells. Cancer Res 2007; 67: 10642-6.

29 Xu FG, Ma QY, Wang Z. Blockade of hedgehog signaling pathway as a therapeutic strategy for pancreatic cancer. Cancer Lett 2009; 283: 119-24.

30 Haaf AT, Bektas N, von Serenyi S, Losen I, Arweiler EC, Hartmann A, et al. Expression of the glioma-associated oncogene homolog (GLI)1 in human breast cancer is associated with unfavourable overall survival. BMC Cancer 2009; 25: 298-301.

31 Mukherjee S, Frolova N, Sadlonova A, Novak Z, Steg A, Page GP, et al. Hedgehog signaling and response to cyclopamine differ in epithelial and stromal cells in benign breast and breast cancer. Cancer Biol Ther 2006; 5: 674-83.

32 Eichenmüller M, Gruner I, Hagl B, Häberle B, Müller-Höcker J, von Schweinitz $D$, et al. Blocking the hedgehog pathway inhibits hepatoblastoma growth. Hepatology 2009; 49: 482-90.

33 Ma X, Sheng T, Zhang Y, Zhang X, He J, Huang S, et al. Hedgehog signaling is activated in subsets of esophageal cancers. Int J Cancer 2006; 118: 139-48.

34 Sicklick JK, Li YX, Jayaraman A, Kannangai R, Qi Y, Vivekanandan P, et al. Dysregulation of the Hedgehog pathway in human hepatocarcinogenesis. Carcinogenesis 2006; 27: 748-57.

35 Huang S, He J, Zhang X, Bian Y, Yang L, Xie G, et al. Activation of the hedgehog pathway in human hepatocellular carcinomas. Carcinogenesis 2006; 27: 1334-40.

36 Cheng WT, Xu K, Tian DY, Zhang ZG, Liu L, Chen Y. Role of hedgehog signaling pathway in proliferation and invasiveness of hepatocellular carcinoma cells. Int J Oncol 2009; 34:829-36.

37 Tada M, Kanai F, Tanaka Y, Tateishi K, Ohta M, Asaoka Y, et al. Downregulation of hedgehog-interacting protein through genetic and epigenetic alterations in human hepatocellular carcinoma. Clin Cancer Res 2008; 14: 3768-76.

$38 \mathrm{Kim}$ Y, Yoon JW, Xiao X, Dean NM, Monia BP, Marcusson EG. Selective down-regulation of glioma-associated oncogene 2 inhibits the proliferation of hepatocellular carcinoma cells. Cancer Res 2007; 67: 3583-93.

39 Kim HY, Cho HK, Hong SP, Cheong J. Hepatitis B virus X protein stimulates the Hedgehog-Gli activation through protein stabilization and nuclear localization of Gli1 in liver cancer cells. Cancer Lett 2011; 309: 176-84.

40 Chen X, Lingala S, Khoobyari S, Nolta J, Zern MA, Wu J. Epithelial mesenchymal transition and hedgehog signaling activation are associated with chemoresistance and invasion of hepatoma subpopulations. J Hepatol 2010; 55: 838-45.

41 Zheng X, Yao Y, Xu Q, Tu K, Liu Q. Evaluation of glioma-associated 
oncogene 1 expression and its correlation with the expression of sonic hedgehog, E-cadherin and S100a4 in human hepatocellular carcinoma. Mol Med Report 2010; 3: 965-70.

42 Philips GM, Chan IS, Swiderska M, Schroder VT, Guy C, Karaca GF, et al. Hedgehog signaling antagonist promotes regression of both liver fibrosis and hepatocellular carcinoma in a murine model of primary liver cancer. PLoS One 2011; 6: e23943.

43 Elia D, Madhala D, Ardon E, Reshef R, Halevy O. Sonic hedgehog promotes proliferation and differentiation of adult muscle cells: Involvement of MAPK/ERK and PI3K/Akt pathways. Biochim Biophys Acta 2007; 1773: 1438-46.

44 Schnidar H, Eberl M, Klingler S, Mangelberger D, Kasper M, HauserKronberger $\mathrm{C}$, et al. Epidermal growth factor receptor signaling synergizes with Hedgehog/GLI in oncogenic transformation via activation of the MEK/ERK/JUN pathway. Cancer Res 2009; 69: 1284-92.

45 Chang H, Li Q, Moraes RC, Lewis MT, Hamel PA. Activation of ERK by sonic hedgehog is independent of canonical hedgehog signaling. Int J Biochem Cell Biol 2010; 42: 1462-71.

46 Seto M, Ohta M, Asaoka Y, Ikenoue T, Tada M, Miyabayashi K, et al. Regulation of the hedgehog signaling by the mitogen-activated protein kinase cascade in gastric cancer. Mol Carcinog 2009; 48: 703-12.

47 Donadio AC, Remedi MM, Susperreguy S, Frede S, Gilardoni MB, Tang $\mathrm{Y}$, et al. Extracellular matrix metalloproteinase inducer and matrix metalloproteinases (MMPs) as regulators of tumor-host interaction in a spontaneous metastasis model in rats. Histochem Cell Biol 2008; 130: 1155-64.
48 Cortes-Reynosa P, Robledo T, Macias-Silva M, Wu SV, Salazar EP. Src kinase regulates metalloproteinase- 9 secretion induced by type IV collagen in MCF-7 human breast cancer cells. Matrix Biol 2008; 27 : 220-31.

49 Wang K, Pan L, Che X, Cui D, Li C. Sonic Hedgehog/GLI signaling pathway inhibition restricts cell migration and invasion in human gliomas. Neurol Res 2010; 32: 975-80.

50 Onishi H, Kai M, Odate S, Iwasaki H, Morifuji Y, Ogino T, et al. Hypoxia activates the hedgehog signaling pathway in a ligand-independent manner by upregulation of Smo transcription in pancreatic cancer. Cancer Sci 2011; 102: 1144-50.

51 Huang XH, Chen JS, Wang Q, Chen XL, Wen L, Chen LZ, et al. miR338-3p suppresses invasion of liver cancer cell by targeting smoothened. J Pathol 2011; 225: 463-72.

52 Thorgeirsson SS, Grisham JW. Molecular pathogenesis of human hepatocellular carcinoma. Nat Genet 2002; 31: 339-46.

53 Thomas MB, Zhu AX. Hepatocellular carcinoma: the need for progress. J Clin Oncol 2005; 23: 2892-9.

54 Grieco A, Pompili M, Caminiti G, Miele L, Covino M, Alfei B, et al. Prognostic factors for survival in patients with early-intermediate hepatocellular carcinoma undergoing non-surgical therapy: comparison of Okuda, CLIP, and BCLC staging systems in a single Italian centre. Gut 2005; 54: 411-8.

55 Kessenbrock K, Plaks V, Werb Z. Matrix metalloproteinases: regulators of the tumor microenvironment. Cell 2010; 141: 52-67. 